Published in final edited form as:

J Neurooncol. 2011 February ; 101(3): 379-390. doi:10.1007/s11060-010-0272-z.

\title{
CONVECTION ENHANCED DELIVERY OF CARBOPLATIN IN COMBINATION WITH RADIOTHERAPY FOR THE TREATMENT OF BRAIN TUMORS
}

\author{
Weilian Yang, \\ Department of Pathology, The Ohio State University 165 Hamilton Hall 1645 Neil Avenue \\ Columbus, Ohio 43210
}

Tianyao Huo,

Department of Pathology, The Ohio State University 165 Hamilton Hall 1645 Neil Avenue Columbus, Ohio 43210

Rolf F. Barth,

Department of Pathology, The Ohio State University 165 Hamilton Hall 1645 Neil Avenue Columbus, Ohio 43210

\section{Nilendu Gupta,}

Department of Radiation Oncology The Ohio State University 300 W 10th Ave Columbus, OH 43210

\begin{abstract}
Michael Weldon,
Department of Radiation Oncology The Ohio State University 300 W 10th Ave Columbus, OH 43210
\end{abstract}

\section{John C. Grecula, Brian D. Ross,}

Department of Radiology, University of Michigan Ann Arbor, MI 48109

\section{Benjamin A. Hoff,}

Department of Radiology, University of Michigan Ann Arbor, MI 48109

\section{Ting-Chao Chou,}

Molecular Pharmacology and Chemistry Program Memorial Sloan-Kettering Cancer Center New York, NY 10021

\section{Julia Rousseau, and}

INSERM, Institute of Neurosciences U836 Equipe 6 Grenoble, France

\section{Hélène Elleaume}

INSERM, Institute of Neurosciences U836 Equipe 6 Grenoble, France

\begin{abstract}
The purpose of this study was to further evaluate the therapeutic efficacy of convection enhanced delivery (CED) of carboplatin in combination with radiotherapy for treatment of the F98 rat
\end{abstract}

(corresponding author) rolf.barth@osumc.edu.

Conflicts of interest: There are no conflicts of interest 
glioma. Tumor cells were implanted stereotactically into the brains of syngeneic Fischer rats, and 13 or $17 \mathrm{~d}$. later carboplatin $(20 \mu \mathrm{g} / 10 \mu \mathrm{L})$ was administered by either CED over 30 min or by Alzet osmotic pumps $(0.5 \mu \mathrm{g} / \mu \mathrm{L} / \mathrm{h}$ for $168 \mathrm{~h}$. ) beginning at $7 \mathrm{~d}$ after tumor implantation. Rats were irradiated with a $15 \mathrm{~Gy}$ fractionated dose $(5 \mathrm{~Gy} \times 3)$ of $6 \mathrm{MV}$ photons to the whole brain beginning on the day after drug administration. Other groups of rats received either carboplatin or $\mathrm{X}$-irradiation alone. The tumor carboplatin concentration following CED of $20 \mu \mathrm{g}$ in $10 \mu \mathrm{L}$ was $10.4 \mu \mathrm{g} / \mathrm{g}$, which was equal to that observed following i.v. administration of $100 \mathrm{mg} / \mathrm{kg}$ b.w. Rats bearing small tumors, treated with carboplatin and X-irradiation, had a mean survival time (MST) of $83.4 \mathrm{~d}$ following CED and $111.8 \mathrm{~d}$ following pump delivery with $40 \%$ of the latter surviving $>180 \mathrm{~d}$ (i.e. cured) compared to $55.2 \mathrm{~d}$ for CED and $77.2 \mathrm{~d}$. for pump delivery of carboplatin alone and $31.8 \mathrm{~d}$ and $24.2 \mathrm{~d}$, respectively, for $\mathrm{X}$-irradiated and untreated controls. There was no microscopic evidence of residual tumor in the brains of all long-term survivors. Not surprisingly, rats with large tumors had much shorter MSTs. Only modest increases in MSTs were observed in animals that received either oral administration or CED of temozolomide plus X-irradiation (23.2 $\mathrm{d}$ and $29.3 \mathrm{~d}$ ) compared to X-irradiation alone. The present survival data, and those previously reported by us, are among the best ever obtained with the F98 glioma model. Initially, they could provide a platform for a Phase I clinical trial to evaluate the safety and potential therapeutic efficacy of CED of carboplatin in patients with recurrent glioblastomas, and ultimately a Phase II trial of carboplatin in combination with radiation therapy.

\section{Introduction}

Cisplatin and carboplatin are highly effective anti-cancer drugs that have been used clinically to treat a variety of malignancies with varying degrees of success [1]. The formation of platinum adducts with nucleophilic sites in DNA molecules causes cell cycle arrest in $\mathrm{G}_{1}$ and $\mathrm{G}_{0}$ [2], and the activation of apoptotic pathways [3]. This can interfere with the repair of radiation-induced damage and may explain the interaction between platinated drugs (cisplatin and carboplatin) and ionizing radiation [4-6]. In studies carried out almost 30 years ago at The Ohio State University with the F98 glioma model, Kaneko et al. [7] reported that systemic administration of cisplatin in combination with radiation therapy (RT) produced a significant prolongation in both median and mean survival times (56 d) and a $25 \%$ increase in life span (\%ILS) of tumor bearing rats compared to radiation alone (44 d). Not long after, the European Organization for Research and Treatment of Cancer carried out a randomized clinical trial involving 285 patients to evaluate the effects of systemically administered cisplatin, with concomitant RT, to patients with supratentorial malignant gliomas [8]. This study failed to demonstrate any improvement in either progression free or overall survival times and it brought to an end any further clinical studies to investigate the combination of cisplatin and photon radiation to treat high grade gliomas.

The use of platinated drugs to treat brain tumors has been limited, not only by their systemic toxicity [9-12], but also by their poor ability to penetrate an intact blood-brain barrier (BBB) [13], as well as those areas where there are microinvasive deposits of tumor. Several approaches have been proposed to bypass the BBB and deliver anticancer drugs directly to brain tumors, thereby increasing tumor drug concentrations and reducing the associated systemic toxicity. These methods include direct intratumoral (i.t.) bolus injection [14] and 
convection enhanced delivery (CED) of drugs via catheters placed into the tumor [14-17]. Using these two approaches, Elleaume and her research team at the European Synchrotron Radiation Facility in Grenoble, France, initiated their studies on intracerebral (i.c.) delivery of either cisplatin or carboplatin in combination with RT using either a synchrotron source or $6 \mathrm{MV}$ photons produced by a linear accelerator (LINAC). They have carried out extensive animal studies demonstrating that i.c. delivery of these drugs, combined with RT have produced the best survival data that ever have been reported with the F98 rat glioma model [18-21].

Although no animal tumor model can exactly simulate human high grade gliomas, the F98 glioma has a number of characteristics that make it an excellent choice for the evaluation of innovative therapeutic modalities. These include its invasive pattern of growth within the brain, lack of immunogenicity, lethality with an inoculum of as few as 10 tumor cells, and until our recent studies, an inability to obtain high cure rates for this tumor by means of a variety of therapeutic modalities, including chemo-, radio- and immunotherapy and gene therapy [22]. Recently, we have reported that the combination of a one week i.c. infusion of carboplatin by Alzet osmotic pumps and RT have resulted in a mean survival time (MST) of $142 \pm 21$ d. with a cure rate of 55\% [20] in F98 glioma bearing Fischer rats. Similar data also have been obtained using short term CED or i.t. injection of cisplatin $[18,21]$ or carboplatin in combination with RT $[19,20]$. The only other comparable survival data with the F98 glioma model were obtained with Boron Neutron Capture Therapy (BNCT) using a combination of two boron containing drugs, boronophenylalanine and sodium borocaptate, administered via the internal carotid artery, together with BBB disruption [23].

In the present study, we have further evaluated the therapeutic efficacy of carboplatin in combination with X-irradiation for treatment of brain tumors using the F98 glioma model. We have extended our previous observations [18-21] relating to this chemoradiotherapeutic modality and have characterized the neurotoxicologic changes associated with this treatment in non-tumor bearing animals. Finally, the efficacy of CED of carboplatin and X-irradiation have been compared to that of temozolomide (TMZ) and RT, which currently is the standard of treatment for high grade gliomas [24,25] and have shown that the former is far more effective than the latter for treatment of the F98 glioma.

\section{Materials and Methods}

\section{F98 rat glioma model}

The F98 rat glioma was derived from an undifferentiated neoplasm that was induced in the progeny of a pregnant CD Fischer rat that had received an injection of N-ethyl-Nnitrosourea. It has been propagated in vitro and in vivo since 1971 and, as described in a recent review [22], it has been used in a wide variety of studies in experimental neurooncology. Molecular markers include deletion of p16/Cdkn2a/Ink4a genes; increased expression of PDGF $\beta$, Ras, EGFR, cyclin D1 and D2 and it is MGMT negative. F98 cells were grown in Dulbecco's modified Eagle's medium (DMEM) (Gibco, Grand Island, NY) supplemented with $10 \%$ fetal bovine serum (FBS) (Hyclone, Logan, UT), 100 units $/ \mathrm{mL}$ penicillin, $100 \mu \mathrm{g} / \mathrm{mL}$ streptomycin and $2 \mathrm{mM} \mathrm{L}$-glutamine. Fischer rats (Animal Production Branch National Cancer Institute, Frederick, MD) weighing 220-240g were used in the 
present study. A stereotactic implantation procedure, which has been described in detail elsewhere [26], was employed. F98 cells at a concentration of either $10^{3}$ cells $/ 10 \mu \mathrm{L}$ (therapy studies) or $10^{5}$ cells $/ 10 \mu \mathrm{L}$ (biodistribution studies) in DMEM containing low gelling temperature agarose were injected into the right caudate nucleus over 10-15 sec through a small entry port of the plastic screw.

\section{Biodistribution of carboplatin in F98 glioma bearing rats}

Eleven to $13 \mathrm{~d}$ after tumor implantation of $10^{5}$ cells, when clinical signs of a progressively growing i.c. tumor were evident, biodistribution studies were initiated. Carboplatin (Hospira Inc. Lake Forrest, IL) was diluted in normal saline to the desired concentrations and was administered by CED at a flow rate of $0.33 \mu \mathrm{L} / \mathrm{min}(20 \mu \mathrm{g} / 10 \mu \mathrm{L})$ over $30 \mathrm{~min}$, using a 10 $\mu \mathrm{L}$ Hamilton syringe, as previously described by us [27]. Immediately following termination of CED, samples of blood were taken, following which the animals were euthanized, their brains were removed, the tumors and brain around tumor (BAT) were carefully dissected out from surrounding normal brain weighed, frozen, and stored at $-70^{\circ} \mathrm{C}$. Samples of liver and kidneys also were taken for Pt determinations. Additional studies also were carried out in tumor bearing rats to determine the biodistribution of carboplatin following intravenous (i.v.) injection via the penile vein of either a myelotoxic dose of $25 \mathrm{mg} / \mathrm{kg}$ b.w. or a lethal does of $100 \mathrm{mg} / \mathrm{kg}$ b.w. [10, 11]. The animals were euthanized $2.5 \mathrm{~h}$ later. Platinum determinations were performed at a later date by means of Inductively Coupled PlasmaOptical Emission Spectroscopy (ICP-OES) (Varian 720-ES, Palo Alto, CA). Based on Pt concentrations, the concentrations of carboplatin (M.W. 371 Da) were calculated by multiplying the Pt values by 1.90 .

\section{Magnetic resonance imaging (MRI)}

In order to determine the distribution of carboplatin in real time following CED, magnetic resonance imaging was carried out. T2-weighted images were acquired before administration of carboplatin admixed with Gd-DTPA (1:70 dilution) (Magnavist, Bayer Health Care Pharmaceuticals). The molecular weights of carboplatin (371 Da) and GdDTPA (938 Da) were close enough to make the latter a reasonable surrogate marker for the former. This was administered by CED over $30 \mathrm{~min}(20 \mu \mathrm{g} / 20 \mu \mathrm{L})$ to F98 glioma bearing rats. MR scans were acquired before treatment, immediately after, and at various times posttreatment using a 7T, horizontal bore Varian (Palo Alto, CA) Direct Drive system with a quadrature rat head coil (Doty Scientific, Inc., Columbia, SC). Anatomical images, used for image localization over the tumor volume, were acquired using a T2-weighted fast spin-echo sequence with the following parameters: TR/TE $=4000 / 60 \mathrm{~ms}$, field of view $(\mathrm{FOV})=30 \mathrm{~mm}$, matrix size $=256 \times 128$, slice thickness $=1 \mathrm{~mm}, 2$ averages. T1-weighted spin-echo images were acquired, for observation of tissue Gd uptake, using the following parameters: TR/ $\mathrm{TE}=510 / 15, \mathrm{FOV}=30 \mathrm{~mm}$, matrix size $=128 \times 128$, thickness $=1 \mathrm{~mm}, 2$ averages. Image analysis was performed using software developed in the Department of Radiology, University of Michigan (MATLAB, The MathWorks, Inc., Natick, MA). Images were interpolated to a matrix size of $256 \times 256$. Volumes of interest (VOI) were drawn on the T1weighted images, encompassing the entire hyper-intense region and sometimes a hypointense region in the center due to Gd susceptibility effects at high concentrations, in order to quantify the volume of distribution of Gd-DTPA in the tissue [28]. 


\section{In vitro studies}

In order to assess the in vitro effects of carboplatin alone or in combination with $\mathrm{X}$ irradiation clonogenic assays have been carried out. To assess the effects of X-irradiation, with or without carboplatin pretreatment, cells were grown in 6-well plates (\#3046, Becton Dickinson Labware, Franklin Lakes, NJ), following which they were trypsinized and transferred to $1.5 \mathrm{~mL}$ microcentrifuge tubes. They then were irradiated with a $7 \mathrm{~Gy}$ dose of 6 MV photons at a dose rate of $2.5 \mathrm{~Gy} / \mathrm{min}$, delivered by a linear accelerator (LINAC) (Siemens Medical Systems, Inc., Malvern, PA) located in the O.S.U. Department of Radiation Oncology. Following this, clonogenic assays were performed. Colonies with $>50$ cells were counted under a dissecting microscope and the surviving fractions (S.F.) for each treatment group were calculated. In a second study, F98 glioma cells were pretreated with either 1 or $2.5 \mu \mathrm{g} / \mathrm{mL}$ of carboplatin followed by X-irradiation with $1,2.5,5,10,15$, and 17.6 Gy. Sensitization enhancement ratios (SER) were calculated by dividing the S.F. of cells that had received X-irradiation alone by the S.F. of those that had been pretreated with carboplatin in order to characterize the dose dependency of combined treatments.

The combination index (CI) method of Chou-Talalay [29-31] has been used to quantify synergism or antagonism using the CompuSyn software of Chou and Martin [32] where Cis $<1,=1,>1$ indicates synergism, additive, and antagonism, respectively. The in vitro combination for X-radiation (varying doses of 1, 2.5, 5, 10, 15, and $17.5 \mathrm{~Gy}$ ) + carboplatin (at $2.5 \mu \mathrm{g} / \mathrm{ml}$ ), was performed (i.e., the non-constant ratio design). At the same time, the dose-effect curves for each treatment alone were carried out to determine the dose-effect parameters. The following values were for X-radiation $\left(\mathrm{D}_{\mathrm{m}}\right)_{1}=1.04 \mathrm{~Gy},(\mathrm{~m})_{1}=1.0877,(\mathrm{r})_{1}$ $=0.982$, and for carboplatin, $\left(\mathrm{D}_{\mathrm{m}}\right)_{2}=0.437 \mu \mathrm{g} / \mathrm{ml},(\mathrm{m})_{2}=1.095$, and $(\mathrm{r})_{2}=0.940$. The $(\mathrm{m})_{1}$, $\left(D_{m}\right)_{1}$ and $(m)_{2},\left(D_{m}\right)_{2}$ and these parameters were used to calculate the $C I$ for combinations, where CIs $<1,=1,>1$ indicate synergism, additive, and antagonism, respectively, using the CompuSyn software.

\section{Neurotoxicologic studies}

All of these studies were carried out in non-tumor bearing Fischer rats. Carboplatin was administered into the striatum either alone or in combination with X-irradiation. Xirradiation was performed, as described in the following section, and consisted of three 5 or 8 Gy fractions, administered over $3 \mathrm{~d}$ beginning 6 or 24 hrs following drug delivery. All animals were monitored clinically and weighed $3 X$ per week. A weight loss of $>20 \%$ was taken as evidence of significant toxicity. Initially, a dose escalation study was carried out. Carboplatin $(10,20$, or $40 \mu \mathrm{g})$ was administered by CED (10 $\mu \mathrm{L}$ at $0.33 \mu \mathrm{L} / \mathrm{min}$ for $30 \mathrm{~min})$ and the animals were euthanized at either $3 \mathrm{~d}$ or 3 weeks later. Next, carboplatin (100 or 200 $\mu \mathrm{g}$ in $200 \mu \mathrm{L}$ ) was administered by Alzet pumps (Durect Corp., Cupertino, CA) over $7 \mathrm{~d}$ (1 $\mu \mathrm{L} / \mathrm{hr}$ ) and the animals were euthanized on $\mathrm{d} 14$. Based on the results of the dose escalation studies, the combination of carboplatin and X-irradiation was evaluated. Rats received carboplatin by CED ( $20 \mu \mathrm{g}$ in $10 \mu \mathrm{L}$ over $30 \mathrm{~min})$, followed by X-irradiation beginning at either 6 or $24 \mathrm{~h}$ later of fractionated doses of $15 \mathrm{~Gy}(3 \times 5 \mathrm{~Gy})$ or $24(3 \times 8 \mathrm{~Gy})$. The animals were euthanized at $3 \mathrm{~d}, 3$ weeks, or 3 months later and their brains were removed, fixed in $10 \%$ buffered formalin and processed for neuropathologic evaluation. Two coronal sections 
of brain $2 \mathrm{~mm}$ rostral and caudal to the injection tract were taken and sections were cut at 4 $\mu$ and stained with hematoxylin and eosin (H\&E).

\section{Therapy studies}

In the first experiment, animals were treated at $13 \mathrm{~d}$ after implantation at which time the estimated tumor size was $20-25 \mathrm{~mm}^{3}$ ("small" tumors). The rats were randomized into six experimental groups of 5-18 animals each and treated as shown in Table 2. In the second experiment, rats were treated at $17 \mathrm{~d}$ after tumor implantation, at which time the calculated tumor volume, based on MRI measurements, was $\sim 60-80 \mathrm{~mm}^{3}$. The animals were randomized into four groups and stratified and treated as shown in Table 3. RT was initiated 14 or 18 days after implantation of F98 glioma cells, and $24 \mathrm{~h}$ following termination of either CED ( $20 \mu \mathrm{g}$ in $10 \mu \mathrm{L}$ at a flow rate of $0.33 \mu \mathrm{L} / \mathrm{min})$ or a $7 \mathrm{~d}$ infusion of carboplatin ( $84 \mu \mathrm{g}$ at a rate of $1 \mu \mathrm{L} / \mathrm{h}$ delivered from $\mathrm{d} 7$ to $\mathrm{d} 13$ ) or normal saline, which was administered as a vehicle control. Rats received a dose of $15 \mathrm{~Gy}$ in three consecutive daily fractions of $5 \mathrm{~Gy}$ each at a dose rate of $2.5 \mathrm{~Gy} / \mathrm{min}$, delivered by a $6 \mathrm{MV}$ Siemens linear accelerator (LINAC) to the whole brain. All irradiated animals were anesthetized with mixture of ketamine (72 mg/kg body weight) and xylazine (12 mg/kg body weight) and placed supine on $5 \mathrm{~cm}$ of solid water equivalent. The animals' heads then were arranged in a concentric circle with 5-6 rats in each irradiation group. A custom cerrobend block was used, limiting the irradiation to the torso to $<5 \%$ of the prescribed dose to the brain. The central circular opening of the block (radiation field) had an effective area of $12 \mathrm{~cm}^{2}$ at a treatment distance of $100 \mathrm{~cm}$ (source-to-bolus distance). The block edge was placed approximately $1.5 \mathrm{~cm}$ from the posterior occipital bone (one fingerbreadth by palpation). One centimeter of tissue equivalent bolus, which had a central opening over the rat's nasal area to permit ventilation, was then placed over their heads. Using an $\alpha / \beta$ ratio of 10 for acute (tumor) effects and 2 for late effects, the $15 \mathrm{~Gy}$ dose was equivalent to $18.75 \mathrm{~Gy}$ in acute effects and $26.25 \mathrm{~Gy}$ in late effects at conventional 2-Gy fractions; the corresponding values for three $8 \mathrm{~Gy}$ fractions were 32.8 and $53.4 \mathrm{~Gy}$. Current standard post surgical treatment for patients with glioblastomas (GBMs) consists of RT with the concomitant administration of temozolomide [24, 25]. In order to compare this treatment to the combination of i.c. carboplatin, we initiated the following study. F98 glioma cells $\left(10^{3}\right)$ were implanted into the brains of 30 Fischer rats and animals were stratified and treated as shown in Table 4. TMZ capsules (Temodar, Bayer Pharmaceutical Corp. Pittsburgh, PA) were dissolved in normal saline containing $10 \%$ dimethylsulfoxide and was administered either orally in daily doses of $80 \mathrm{mg} / \mathrm{kg} \mathrm{b.w}$. for $5 \mathrm{~d}$ by gavage or i.c. by CED (1.5 mg in 15 $\mu \mathrm{L}$ at a flow rate of $0.5 \mu \mathrm{L} / \mathrm{min}$ for $30 \mathrm{~min}$ ).

\section{Evaluation of therapeutic response}

All experimental animals were weighed three times per week and their clinical status was evaluated at the same time. Once the animals had progressively growing tumors, as evidenced by the combination of sustained weight loss, ataxia and peri-orbital hemorrhage, they were euthanized in order to minimize their discomfort. Survival times were determined by adding one day to the time between tumor implantation and euthanization. Rats surviving $>180 \mathrm{~d}$ were designated long term survivors and were euthanized. The brains of all animals in the therapy studies were removed after death, and processed for neuropathologic 
examination, stained with $\mathrm{H} \& \mathrm{E}$, and examined microscopically to assess the neuropathologic changes.

\section{Statistical evaluation of data}

For the in vitro cytotoxicity data and the in vivo biodistribution data, the means and standard deviations (SE) were computed for carboplatin in tumor, brain around tumor (BAT), ipsilateral (tumor bearing) and contralateral (non-tumor bearing) cerebral hemispheres, and blood. To study the effects of treatment on survival of F98 glioma bearing rats, the mean survival time (MST), standard error (SE), and median survival time (MeST) were calculated for each group using the Kaplan-Meier estimate [33] and survival curves also were plotted for each group. An overall log rank test was performed to test for equality of survival curves over the six groups. The a priori hypotheses involved a comparison of CED versus pump delivery of carboplatin $+\mathrm{X}$-irradiation versus $\mathrm{CED}$ of carboplatin or $\mathrm{X}$-irradiation alone in F98 glioma bearing rats. The Wald test was used for these comparisons after fitting the data with a Cox model, with a Bonferroni method of adjustment for the multiple comparisons [34]. The percent increased life span was determined, as previously described [19].

\section{Results}

\section{In vitro cytotoxicity of carboplatin combined with X-irradiation}

The survival plots for cells that were exposed to either carboplatin alone or carboplatin $+\mathrm{X}$ irradiation (7 Gy) are shown in Fig 1A. The S.F. of the glioma cells decreased with increasing doses of carboplatin from 0 to $5 \mu \mathrm{g} / \mathrm{mL}$. The $\mathrm{D}_{10}$ value for cells treated with carboplatin alone was $2.5 \mu \mathrm{g} / \mathrm{mL}$. X-irradiation further reduced the S.F. to 0.0194 . The S.F. was $<0.1 \%$ following treatment with $5 \mu \mathrm{g} / \mathrm{mL}$ of carboplatin either alone or in combination with X-irradiation and this decreased to $<0.0001$ in the presence of $7.5 \mu \mathrm{g} / \mathrm{mL}$ of carboplatin. Based on these studies, it was concluded that a drug concentration of $3.5 \mu \mathrm{g} / \mathrm{mL}$ killed $>>99 \%$ of the tumor cells. The effects of varying doses of X-rays either alone or following pretreatment with either 1 or $2.5 \mu \mathrm{g} / \mathrm{mL}$ carboplatin are shown in Fig. 1B. As expected, the combination produced dose dependent reductions in the S.F.s with a maximum effect of $17.5 \mathrm{~Gy}$ ( $\mathrm{S} . \mathrm{F}=1.17 \times 10^{-3}$ with $1 \mu \mathrm{g}$ and $2.6 \times 10^{-4}$ with $2.5 \mu \mathrm{g}$ of carboplatin). The sensitization enhancement ratios (SER) obtained using carboplatin at a concentration of 1 $\mu \mathrm{g} / \mathrm{mL}$, followed by X-irradiation at $2.5,5$ or $10 \mathrm{~Gy}$, were all very similar $(3.34,2.76$ and 2.88 , respectively). In contrast, when cells were pretreated with a $2.5 \mu \mathrm{g} / \mathrm{mL}$ of carboplatin, there was a marked increase in the SERs observed following irradiation with 2.5, 5, and 10 Gy $(36.75,16.86$, and 13.42 , respectively).

Analysis of the in vitro data using the method of Chou and Talalay [29-31] revealed that the single treatment with carboplatin or $\mathrm{X}$-irradiation alone showed reasonably good $\mathrm{r}$ values ( $r=0.940$ and $r=0.982$, respectively) indicating the assays were carried out properly. The killing effectiveness of X-irradiation was $\mathrm{IC}_{50}=1.04 \mathrm{~Gy}$ and for carboplatin $\mathrm{IC}_{50}=$ $0.437 \mu \mathrm{g} / \mathrm{mL}$. A plot of the X-irradiation data yielded a sigmoidal dose-effect curve $(\mathrm{m}>1)$ and carboplatin alone gave hyperbolic dose-effect curve $(\mathrm{m} \approx 1)$. All six data points for the combination had $\mathrm{CI}$ values ranging from 0.297 to 0.586 , which clearly indicated synergism, as shown by the $\mathrm{F}_{\mathrm{a}}-\mathrm{CI}$ plot (Chou-Talalay plot) (Fig. 2A) and by the normalized 
isobologram (Chou-Chou graphics) (Fig. 2B). Further analysis revealed a dose-reduction index (DRI) of 2.10-6.79 fold for X-irradiation and 4.31-180.4 fold for carboplatin (Fig. 2C), which clearly demonstrated a favorable DRI of $>1$ for the combination. This suggests that there also could be a dose reduction in vivo, which would reduce normal brain toxicity or permit a slight escalation in dose, depending on the maximum tolerated dose.

Furthermore, the toxicities of $\mathrm{X}$-irradiation and carboplatin would not overlap due to the different molecular mechanisms by which they kill cells. Similar experiments also were carried out with varying doses of X-rays, but at a lower concentration of carboplatin $(1 \mu \mathrm{g} / \mathrm{ml})$ (data not shown). In this design, only 2 of 6 data points showed synergism. These results suggest that in future studies, even higher doses of carboplatin and lower doses of Xrays might be even more efficacious than those that were used in the present study.

\section{Biodistribution of carboplatin}

As determined by ICP-OES, the distribution of carboplatin in tumor, normal, brain, blood, liver and kidney are shown in Table 1 . Following CED of $20 \mu \mathrm{g}$ of carboplatin, the tumor drug concentration was $10.4 \mu \mathrm{g} / \mathrm{g}$, low in normal brain and undetectable in blood, kidney and liver. Following i.v. administration of carboplatin at concentrations of $25100 \mathrm{mg} / \mathrm{kg}$ b.w., the tumor drug concentrations were 4.1 and $9.8 \mu \mathrm{g} / \mathrm{g}$, respectively, and the normal brain concentrations were 8.4 and $11.3 \mu \mathrm{g} / \mathrm{g}$. In contrast to the CED data, following i.v. injection, carboplatin concentrations in the liver and kidneys were very high (Table 1). It is noteworthy that the tumor drug concentrations were equivalent following CED of $20 \mu \mathrm{g}$ and i.v. administration of $20 \mathrm{mg}$ of carboplatin ( 10.4 and $9.8 \mu \mathrm{g} / \mathrm{g}$, respectively), despite the fact that there was a 1,000 fold difference in the amount administered (20 $\mu \mathrm{g}$ versus $20,000 \mu \mathrm{g})$.

The distribution of a carboplatin-Gd-DTPA mixture following CED was determined by T1weighted MRI studies. The volumes of distribution $\left(\mathrm{V}_{\mathrm{d}}\right)$, as a function of time were calculated from T1-weight images following CED of $20 \mu \mathrm{g}$ carboplatin mixed with $\mathrm{Gd}$ DTPA (Fig. 3A). The $\mathrm{V}_{\mathrm{d}}$ was $278-377 \mathrm{~mm}^{3}$ between $0.5-3$ hours following CED of $20 \mu \mathrm{l}$ of the infusates and the $\mathrm{V}_{\mathrm{d}} / \mathrm{V}_{\mathrm{i}}$ ratio ranged from 13.3 to 18.8 . A representative MR image is shown in Fig. 3B. There was intense uptake of Gd-DTPA in the tumor and in the peritumoral white matter indicating more efficient dispersion of the mixture by CED than would have been possible by direct i.t. injection.

\section{Neurotoxicologic evaluation}

The neuropathologic findings were all based on microscopic examination of H\&E stained coronal sections, since there were no grossly evident pathologic changes. Carboplatin was administered by either CED $(10 \mu \mathrm{L})$ at a flow rate of $0.33 \mu \mathrm{L} / \mathrm{min}$ for $30 \mathrm{~min}$ or by Alzet osmotic pumps (Durect Corp., Cupertino, CA) over 7 days (at a flow rate of $1 \mu \mathrm{L} / \mathrm{hr}$ ) and the rats were euthanized either on $\mathrm{d} 14$ or $\mathrm{d} 21$. The brains of rats that received a dose of $40 \mu \mathrm{g}$ of carboplatin by CED or $168 \mu \mathrm{g}$ over $7 \mathrm{~d}$ by Alzet pumps showed focal necrosis, neuronal loss and edema at the site of infusion (Fig. 4B, C, D). In contrast, the brains of animals that received $20 \mu \mathrm{g}$ of carboplatin by CED over $30 \mathrm{~min}$ or $84 \mu \mathrm{g}$ over $7 \mathrm{~d}$ by Alzet pumps only showed minimal reactive inflammation and gliosis in the regions immediately surrounding the needle track and these doses subsequently were used in the therapy studies. The combined effect of carboplatin and X-irradiation then was evaluated. Rats that had received 
carboplatin by CED ( $20 \mu \mathrm{g}$ in $10 \mu \mathrm{L}$ over $30 \mathrm{~min}$ ) or Alzet pumps ( $84 \mu \mathrm{g}$ over $168 \mathrm{~h}$ ) followed $24 \mathrm{~h}$ later by fractionated doses of $15 \mathrm{~Gy}(3 \times 5 \mathrm{~Gy})$ showed no histopathologic evidence of neurotoxicity at $3 \mathrm{~d}, 3$ weeks, or 3 months following irradiation. In contrast, animals that received $40 \mu \mathrm{g}$ of carboplatin either alone or in combination with $15 \mathrm{~Gy}$ of irradiation ( $3 \times 5 \mathrm{~Gy})$ showed evidence of significant neurotoxicity (Fig. 4B, C, D).

\section{Therapeutic efficacy of carboplatin alone or in combination with X-irradiation}

Two experiments were carried out to assess therapeutic efficacy. In the first, rats were treated at $13 \mathrm{~d}$ following implantation of $10^{3} \mathrm{~F} 98$ glioma cells at which time the tumor volume was $25-30 \mathrm{~mm}^{3}$. The survival data are summarized in Table 2 and the KaplanMeier survival plots are shown in Fig 5A. Rats that received carboplatin alone by CED had a MST of $55.2 \pm 7.8 \mathrm{~d}$, which was significantly longer than that of X-irradiated rats $(31.8 \pm$ $1.2 \mathrm{~d})(\mathrm{p}<0.001)$. Animals that received CED of carboplatin in combination with $\mathrm{X}$ irradiation had a MST of $83.4 \pm 13.1 \mathrm{~d}$, with $22 \%$ of the rats surviving for $180 \mathrm{~d}$ at which time they were considered to be cured. Animals that received $84 \mu \mathrm{g}$ carboplatin over $7 \mathrm{~d}$ by Alzet osmotic pumps had a MST of $77.2 \pm 23.0 \mathrm{~d}$ without X-irradiation and $111.8 \pm 31.5 \mathrm{~d}$ in combination with X-irradiation and $22 \%$ of the latter survived to $180 \mathrm{~d}$, at which time they were euthanized. The improved survival data of these animals in part may have been due to the fact that therapy was initiated on $\mathrm{d} 7$ at which time they had very small tumors. In the second experiment, rats were treated at $17 \mathrm{~d}$ following implantation of $10^{3} \mathrm{~F} 98$ glioma cells at which time tumor size was $\sim 60-80 \mathrm{~mm}^{3}$. The survival data of these animals are summarized in Table 3 and the Kaplan-Meier survival plots are shown in Fig. 5B. The MSTs of untreated and X-irradiated rats were equivalent to those obtained in the first experiment. In contrast, rats bearing larger tumors that had received carboplatin by CED had a MST of $34.9 \pm 8.2 \mathrm{~d}$ and those that received the combination treatment had a MST of $44.9 \pm 3.5 \mathrm{~d}$. These results clearly demonstrated that tumor size was an important determinant of the response to therapy and animals with small tumors were more responsive than those with larger tumors. None of the brains of the cured rats showed any evidence of residual tumor cells. There was a spectrum of neuropathologic changes including scattered foci of basophilic "debris" and dystrophic calcification, loss of varying amounts of white matter, and occasional lymphocytes (Fig. 4A). Therapeutic response after therapy with temozolomide alone or in combination with $\mathrm{X}$-irradiation

The survival data following oral administration or CED of TMZ with or without Xirradiation in F98 glioma bearing rats are summarized in Table 4. X-irradiated rats had a MST $21.2 \pm 0.8 \mathrm{~d}$ compared to MSTs of $17.0 \pm 1.2 \mathrm{~d}$ and $18.2 \pm 1.7 \mathrm{~d}$, and TMZ administered either orally or by gavage 23.2 and $29.3 \pm 5.0 \mathrm{~d}$, and for those that received it in combination with $\mathrm{X}$-irradiation. No statistically significant therapeutic gain was seen in rats that had received TMZ compared to $\mathrm{X}$-irradiation alone ( $\mathrm{p}>0.6)$.

\section{Discussion}

The purpose of the present study was to extend observations, previously reported by several of us $[19,20]$ on the efficacy of i.c. CED of carboplatin in combination with X-irradiation for the treatment of the F98 glioma. Biodistribution studies revealed that CED of $20 \mu \mathrm{g}$ of 
carboplatin to F98 glioma bearing rats resulted in a tumor drug concentration of $10.4 \mu \mathrm{g} / \mathrm{gm}$, which was identical to that obtained following i.v. administration of $100 \mathrm{mg} / \mathrm{kg}$ b.w. ( 20 $\mathrm{mg} / \mathrm{rat})$, a lethal dose [11], that was 1,000 times greater than that administered by CED. This clearly demonstrated the ability of CED to achieve tumor drug concentrations that exceeded by 3 orders of magnitude those that could be attained following systemic administration. In vitro pre-exposure of F98 cells to $5 \mu \mathrm{g}$ of carboplatin, followed by a 7 Gy dose of X-rays, reduced the S.F. to $<0.0006$. This can be correlated with the prolonged survival times that were seen in our in vivo studies where the estimated carboplatin concentration after CED was $10.4 \mu \mathrm{g}$ and the total radiation dose was $15 \mathrm{~Gy}$. As shown in Fig. 2, the in vitro demonstration of synergy provides proof-of-concept and the rationale for the design of a clinical trial, which would include CED of carboplatin in combination with X-irradiation.

Rats bearing small tumors had longer MSTs than those observed in animals bearing large tumors. One possible explanation for this was less effective dispersion of carboplatin within larger tumors. Although CED was superior to direct i.t. injection [18], this technique for drug delivery to the brain is still a work in progress and there is a significant need for improvement [35]. The increased interstitial fluid pressure in both human and rodent intracranial (i.c.) tumors [36], as well as constituents of the extracellular matrix, which may impede the dispersion of therapeutic agents within the tumor [37], are significant problems that must be surmounted. These factors may in part explain differences in the therapeutic response of rats bearing small versus large tumors. Prolonged infusion of carboplatin by means of Alzet osmotic pumps yielded the longest MST, and 2 of 5 rats were cured of their tumors. However, it should be pointed out that therapy was initiated on $\mathrm{d} 7$ at which time the tumor size was much smaller than that on $\mathrm{d} 14$, when CED was initiated. In contrast to carboplatin, TMZ readily crosses the BBB [38]. This clearly was evident from our therapy study comparing oral administration of TMZ by gavage with i.c. CED of the drug. Rats that received TMZ by CED in combination with X-irradiation had a slightly longer MST compared to that of animals that had received the drug orally with a broadening of the range. These results are in agreement with recently reported studies that compared the therapeutic efficacy of i.c. TMZ impregnated wafers or oral TMZ, alone or in combination with Xirradiation in F98 glioma bearing rats [39]. Modest increases in survival times were seen in those animals that received i.c. TMZ plus X-irradiation compared to those that received it orally, but this was not statistically significant when compared to X-irradiation alone. It is noteworthy that in the present study the MSTs obtained with the combination of carboplatin and X-irradiation were far superior to those obtained with TMZ and photon irradiation. This correlates well with our in vitro data that demonstrated a tenfold increase in the SER when cells were pretreated with carboplatin at a concentration of $2.5 \mu \mathrm{g} / \mathrm{mL}$ and irradiated with 2.5 Gy of X-rays (36.75) compared to 3.34 when they were treated with $1 \mu \mathrm{g} / \mathrm{mL}$. Furthermore, the SER decreased as a function of the X-ray dose. As shown in Fig. 2, analysis of the in vitro cell survival data using the Chou-Talalay method clearly revealed that the combination of carboplatin and $\mathrm{X}$-irradiation was strongly synergistic.

Our chemotherapy results in the F98 glioma model are in good agreement with those previously reported by Olivi et al. [40] using carboplatin-loaded biodegradable polymers for treatment of this same tumor. They reported therapeutic efficacy was dose-related with an 
increasing number of early deaths associated with escalating doses of the drug up to $0.5 \mathrm{mg}$. In our study, using Alzet osmotic pumps, the amount of carboplatin administered was $84 \mu \mathrm{g}$, which was below that used by Olivi et al. [40] This was well tolerated and resulted in $20 \%$ long-term survivors in combination with RT and $17 \%$ without it. At least with chemosensitive tumors, there has been a clear relationship between the therapeutic response and increasing both the concentration and duration of exposure to carboplatin [40-42] or cisplatin [43]. Using the RG2 rat glioma model, with tumor cells implanted into the cortex, Carson and his co-workers have shown that carboplatin, delivered by osmotic pumps into the brainstems of rats bearing F98 gliomas, significantly enhanced their survival [44, 45]. It is noteworthy that in this study the brainstem was not damaged by direct infusion of $200 \mu \mathrm{L}$ of carboplatin $(0.5 \mathrm{mg} / \mathrm{mL})$, and that there was no neurotoxicity until a lethal dose (dose $\geq 1.0 \mathrm{mg} / \mathrm{mL}$ ) was administered. However, in a recently reported study by the same group, up to 3 catheters were used to infuse carboplatin into the brainstems of non-tumor bearing Fischer rats [46] using Alzet ${ }^{\mathrm{TM}}$ osmotic pumps. Animals that received carboplatin showed some relevant neurological impairment during infusion compared to controls, and this persisted. It was concluded that carboplatin related neurotoxicity was important if the drug was infused into functional, highly eloquent structures of the brainstem.

Degen et al. [47] carried out a dose-escalation study of CED of carboplatin into the striatum of non-tumor bearing rats. No toxicity was observed with doses of 0.1 and $1.0 \mathrm{mg} / \mathrm{mL}$, but occurred in rats that had received $10 \mu \mathrm{L}$ of the highest dose of carboplatin $(100 \mu \mathrm{g})$ with 2 of 4 of these animals dying. Tange et al. [48] recently reported on the therapeutic efficacy of carboplatin $(0.1 \mathrm{mg} / \mathrm{mL})$ administered by means of Alzet osmotic pumps tumors $(1 \mu \mathrm{L} / \mathrm{h}$ during $7 \mathrm{~d}$.) to $9 \mathrm{~L}$ gliosarcoma bearing rats. Serial MR imaging was carried out and this showed significantly smaller tumor volumes and an increased MST of $60 \mathrm{~d}$. with a subset (3 of 8 rats) of long term surviving $>100 \mathrm{~d}$. These two studies are in concordance with our previously published data on i.c. delivery of carboplatin $[19,20]$, as well as those reported in the present study.

There is a paucity of data on the effects of direct administration of cisplatin or carboplatin into the human brain. There are only two clinical reports describing the direct i.c. infusion of platinated drugs for glioma treatment. Bouvier et al. [49] infused $8.3 \mathrm{mg}$ of cisplatin over 10 days into the left frontoparietal lobe of a patient with a recurrent GBM using 68 catheters, each connected to an Alzet pump. No adverse side effects associated with catheter implantation, chemotherapy, or catheter removal were reported. Nevertheless, the tumor recurred and the patient died 6 months later. However, it should be pointed out that these studies were carried out almost 25 years ago at which time the rules for clinical studies were quite different than they are today. Alzet pumps were not then nor are they now manufactured for human use. Furthermore, they have not been approved by the Food and Drug Administration for this purpose, which effectively precludes their clinical use. In the second study [50], cisplatin was incorporated into biodegradable polymers and these were placed into the resection cavity following subtotal removal of the GBM. The patients received RT ( 2 Gy fractions for a total dose of $60 \mathrm{~Gy}$ ) beginning two weeks after surgery. Complete biodegradation of the cisplatin containing discs had occurred by 4-5 weeks following their placement. Although there was no autopsy data to indicate what, if any, 
neuropathologic changes had occurred in the treated patients, clinically the treatment appeared to have been well-tolerated and significantly increased $(p=0.00001)$ the median survival time ( $427 \mathrm{~d}$ compared to $211 \mathrm{~d}$ ) in GBM patients who had received RT alone.

Where do we go from here? The major problem associated with any therapeutic study carried out using rodent brain tumor models is their relevancy to the treatment of patients with brain tumors [51]. However, one thing is reasonably certain: If it does not "work" in rodents, it probably will not work in humans. The rat brain weighs approximately $1.2 \mathrm{~g}$ and a human brain weighs 1,200 g, a thousand-fold difference. Although CED has been effective in improving the distribution of a variety of agents in rats with brain tumors, its effectiveness in humans has been much more problematic [14-17]. However, direct i.c. delivery of therapeutic agents, which bypass the BBB, results in much higher concentrations in the brain tumor and concomitantly lower concentrations in extracranial sites thereby reducing systemic toxicity. This was strikingly demonstrated in the present study where 20 $\mu \mathrm{g}$ of carboplatin administered i.c. by CED resulted in the same tumor drug concentrations as that achieved with a thousand-fold greater amount administered i.v. We have shown both in the present and in our previous studies $[19,20]$ that i.c. delivery of carboplatin in combination with $\mathrm{X}$-irradiation can produce prolonged survival and even cures of F98 glioma bearing rats. However, the challenge will be to further optimize the delivery and dosing paradigms for both free drug and carboplatin containing nanovehicles, which we currently are evaluating, so that we can obtain comparable survival data in animals with large tumors.

\section{Acknowledgments}

We thank Dr. Abhik Ray Chaudhury for reviewing selected histologic sections with one of us (RFB), Mr. Andrew Pultz, OSU James Cancer Hospital Outpatient Pharmacy for generously providing us with carboplatin, Mr. Shawn Scully for assistance in taking photomicrographs, Dr. Richard Hill for his comments relating to our in vitro studies, and finally Ms. Michelle Van Fossen for expert secretarial assistance in the preparation of this manuscript. Support for this study was generously provided by the Musella Foundation, the Grey Ribbon Crusade, the Have a Chance Foundation, The Brad Kaminsky Foundation, and The Ohio State University Department of Pathology.

\section{REFERENCES}

1. Kelland L. The resurgence of platinum-based cancer chemotherapy. Nat Rev Cancer. 2007; 7:573584. [PubMed: 17625587]

2. Chadwick KH, Leenhouts HP, Szumiel I, et al. An analysis of the interaction of a platinum complex and radiation with $\mathrm{CHO}$ cells using the molecular theory of cell survival. Int J Radiat Biol Relat Stud Phys Chem Med. 1976; 30:511-524. [PubMed: 1087292]

3. Chater S, Amara S, Moussata D, et al. Differential effects of ionizing radiation and platinumderivative chemotherapy on apoptotic pathways in testicular germ cells. Int J Radiat Biol. 2007; 83:269-278. [PubMed: 17575954]

4. Stewart DJ, Molepo J, Eapen L, et al. Cisplatin and radiation in the treatment of tumors of the central nervous system: pharmacological considerations and results of early studies. Int J Radiat Biol. 1993; 28:531-542.

5. Yapp DT, Lloyd DK, Zhu J, et al. The potentiation of the effect of radiation treatment by intratumoral delivery of cisplatin. Int J Radiat Oncol Biol Phys. 1998; 42:413-420. [PubMed: 9788424]

6. Yunhua B, Xiaochao Y, Jindong W, et al. Cisplatin as a radiosensitizer in clinical practice: a pilot study. Tumori. 1991; 77:21-24. [PubMed: 2017793] 
7. Kaneko S, Clendenon NR, Kartha M. Experimental study in a rat brain tumor by combined treatment with cis-DDP and irradiation. Neurol Med Chir (Tokyo). 1983; 23:917-923. [PubMed: 6204222]

8. Cisplatin does not enhance the effect of radiation therapy in malignant gliomas. EORTC Brain Tumor Group. Eur J Cancer. 1991; 27:568-571. Anonymous. [PubMed: 1828963]

9. DeConti RC, Toftness BR, Lange RC, et al. Clinical and pharmacological studies with cisdiamminedichloroplatinum (II). Cancer Res. 1973; 33:1310-1315. [PubMed: 4515709]

10. Husain K, Whitworth C, Rybak LP. Time response of carboplatin-induced nephrotoxicity in rats. Pharmacol Res. 2004; 50:291-300. [PubMed: 15225673]

11. Siddik ZH, Boxall FE, Harrap KR. Hematological toxicity of carboplatin in rats. Br J Cancer. 1987; 55:375-379. [PubMed: 3555590]

12. McWhinney SR, Goldberg RM, McLeod HL. Platinum neurotoxicity pharmacogenetics. Mol Cancer Ther. 2009; 8:10-16. [PubMed: 19139108]

13. Muldoon LL, Soussain C, Jahnke K, et al. Chemotherapy delivery issues in central nervous system malignancy: a reality check. J Clin Oncol. 2007; 25:2295-2305. [PubMed: 17538176]

14. Sampson JH, Akabani G, Friedman AH, et al. Comparison of intratumoral bolus injection and convection-enhanced delivery of radiolabeled antitenascin monoclonal antibodies. Neurosurg Focus. 2006; 20:E14. [PubMed: 16709019]

15. Hall WA, Sherr GT. Convection-enhanced delivery: targeted toxin treatment of malignant glioma. Neurosurg Focus. 2006; 20:E10. [PubMed: 16709015]

16. Patel SJ, Shapiro WR, Laske DW, et al. Safety and feasibility of convection-enhanced delivery of Cotara for the treatment of malignant glioma: initial experience in 51 patients. Neurosurgery. 2005; 56:1243-1252. [PubMed: 15918940]

17. Sampson JH, Brady ML, Petry NA, et al. Intracerebral infusate distribution by convectionenhanced delivery in humans with malignant gliomas: descriptive effects of target anatomy and catheter positioning. Neurosurgery. 2007; 60:89-98.

18. Biston MC, Joubert A, Adam JF, et al. Cure of Fischer rats bearing radioresistant F98 glioma treated with cis-platinum and irradiated with monochromatic synchrotron X-rays. Cancer Res. 2004; 64:2317-2323. [PubMed: 15059878]

19. Rousseau J, Boudou C, Barth RF, et al. Enhanced survival and cure of F98 glioma-bearing rats following intracerebral delivery of carboplatin in combination with photon irradiation. Clin Cancer Res. 2007; 13:5195-5201. [PubMed: 17726137]

20. Rousseau J, Barth RF, Moeschberger ML, et al. Efficacy of intracerebral delivery of carboplatin in combination with photon irradiation for treatment of F98 glioma-bearing rats. Int J Radiat Oncol Biol Phys. 2009; 73:530-536. [PubMed: 19147017]

21. Rousseau J, Barth RF, Fernandez M, et al. Efficacy of intracerebral delivery of cisplatin in combination with photon irradiation for treatment of brain tumors. J Neurooncol. 2009 DOI 10.1007/s11060-11009-10074-11063.

22. Barth RF, Kaur B. Rat brain tumor models in experimental neuro-oncology: the C6, 9L, T9, RG2, F98, BT4C, RT-2 and CNS-1 gliomas. J Neurooncol. 2009; 94:299-312. [PubMed: 19381449]

23. Barth RF, Yang W, Rotaru JH, et al. Boron neutron capture therapy of brain tumors: enhanced survival and cure following blood-brain barrier disruption and intracarotid injection of sodium borocaptate and boronophenylalanine. Int J Radiat Oncol Biol Phys. 2000; 47:209-218. [PubMed: 10758326]

24. Stupp R, Mason WP, van den Bent MJ, et al. Radiotherapy plus concomitant and adjuvant temozolomide for glioblastoma. N Engl J Med. 2005; 352:987-996. [PubMed: 15758009]

25. Stupp R, Hegi ME, Mason WP, et al. Effects of radiotherapy with concomitant and adjuvant temozolomide versus radiotherapy alone on survival in glioblastoma in a randomised phase III study: 5-year analysis of the EORTC-NCIC trial. Lancet Oncol. 2009; 10:459-466. [PubMed: 19269895]

26. Yang W, Barth RF, Carpenter DE, et al. Enhanced delivery of boronophenylalanine for neutron capture therapy by means of intracarotid injection and blood-brain barrier disruption. Neurosurgery. 1996; 38:985-992. [PubMed: 8727825] 
27. Yang W, Barth RF, Adams DM, et al. Convection-enhanced delivery of boronated epidermal growth factor for molecular targeting of EGF receptor-positive gliomas. Cancer Res. 2002; 62:6552-6558. [PubMed: 12438250]

28. Ross BD, Zhao YJ, Neal ER, et al. Contributions of cell kill and posttreatment tumor growth rates to the repopulation of intracerebral 9L tumors after chemotherapy: an MRI study. Proc Natl Acad Sci U S A. 1998; 95:7012-7017. [PubMed: 9618530]

29. Chou TC. Theoretical basis, experimental design, and computerized simulation of synergism and antagonism in drug combination studies. Pharmacol Rev. 2006; 58:621-681. [PubMed: 16968952]

30. Chou TC, Talalay P. Quantitative analysis of dose-effect relationships: the combined effects of multiple drugs or enzyme inhibitors. Adv Enzyme Regul. 1984; 22:27-55. [PubMed: 6382953]

31. Chou TC. Drug combination studies and their synergy quantification using the Chou-Talalay method. Cancer Res. 2010; 70:440-446. [PubMed: 20068163]

32. Chou, TC.; Martin, N. PC Software and User's Guide: a computer program for quantitation of synergism and antagonism in drug combinations, and the determination of IC50, ED50 and LD50 values. ComboSyn; Paramus (NJ): 2005.

33. Madsen, RW.; Moeschberger, ML. Statistical concepts. Prentice Hall; Englewood Cliffs, NJ: 1986.

34. Klein, JP.; Moeschberger, ML. Survival analysis techniques for censored and truncated data. 2nd edition.. Springer; New York: 2003.

35. Bidros DS, Liu JK, Vogelbaum MA. Future of convection-enhanced delivery in the treatment of brain tumors. Future Oncol. 2009; 6:117-125. [PubMed: 20021213]

36. Boucher Y, Salehi H, Witwer B, et al. Interstitial fluid pressure in intracranial tumours in patients and in rodents. Br J Cancer. 1997; 75:829-836. [PubMed: 9062403]

37. Netti PA, Berk DA, Swartz MA, et al. Role of extracellular matrix assembly in interstitial transport in solid tumors. Cancer Res. 2000; 60:2497-2503. [PubMed: 10811131]

38. Newlands ES, Stevens MF, Wedge SR, et al. Temozolomide: a review of its discovery, chemical properties, pre-clinical development and clinical trials. Cancer Treat Rev. 1997; 23:35-61.

[PubMed: 9189180]

39. Recinos VR, Tyler BM, Bekelis K, et al. Combination of intracranial temozolomide with intracranial carmustine improves survival when compared with either treatment alone in a rodent glioma model. Neurosurgery. 2010; 66:530-537. [PubMed: 20173548]

40. Olivi A, Ewend MG, Utsuki T, et al. Interstitial delivery of carboplatin via biodegradable polymers is effective against experimental glioma in the rat. Cancer Chemother Pharmacol. 1996; 39:90-96. [PubMed: 8995504]

41. Emerich DF, Winn SR, Snodgrass P, et al. Injectable chemotherapeutic microspheres and glioma II: Enhanced survival following implantation into deep inoperable tumors. Pharm Res. 2000; 17:776-781. [PubMed: 10990194]

42. Emerich DF, Winn SR, Bartus RT. Injection of chemotherapeutic microspheres and glioma. IV: Eradicating tumors in rats. Cell Transplant. 2002; 11:47-54. [PubMed: 12095219]

43. Yapp DT, Lloyd DK, Zhu J, et al. Cisplatin delivery by biodegradable polymer implant is superior to systemic delivery by osmotic pump or i.p. injection in tumor-bearing mice. Anticancer Drugs. 1998; 9:791-796. [PubMed: 9840725]

44. Carson BS Sr. Wu Q, Tyler B, et al. New approach to tumor therapy for inoperable areas of the brain: chronic intraparenchymal drug delivery. J Neurooncol. 2002; 60:151-158. [PubMed: 12635662]

45. Khan A, Jallo GI, Liu YJ, et al. Infusion rates and drug distribution in brain tumor models in rats. J Neurosurg. 2005; 102:53-58. [PubMed: 16206734]

46. Thomale UW, Tyler B, Renard VM, et al. Local chemotherapy in the rat brainstem with multiple catheters: a feasibility study. Childs Nerv Syst. 2009; 25:21-28. [PubMed: 18690465]

47. Degen JW, Walbridge S, Vortmeyer AO, et al. Safety and efficacy of convection-enhanced delivery of gemcitabine or carboplatin in a malignant glioma model in rats. J Neurosurg. 2003; 99:893-898. [PubMed: 14609170]

48. Tange Y, Miyazaki M, Iwata J, et al. Novel antitumor effect of carboplatin delivered by intracerebral microinfusion in a rat malignant glioma model. Neurol Med Chir (Tokyo). 2009; 49:572-579. [PubMed: 20035131] 
49. Bouvier G, Penn RD, Kroin JS, et al. Direct delivery of medication into a brain tumor through multiple chronically implanted catheters. Neurosurgery. 1987; 20:286-291. [PubMed: 3031539]

50. Sheleg SV, Korotkevich EA, Zhavrid EA, et al. Local chemotherapy with cisplatin-depot for glioblastoma multiforme. J Neurooncol. 2002; 60:53-59. [PubMed: 12416546]

51. de Jong M, Maina T. Of mice and humans: are they the same?--Implications in cancer translational research. J Nucl Med. 2010; 51:501-504. [PubMed: 20237033] 

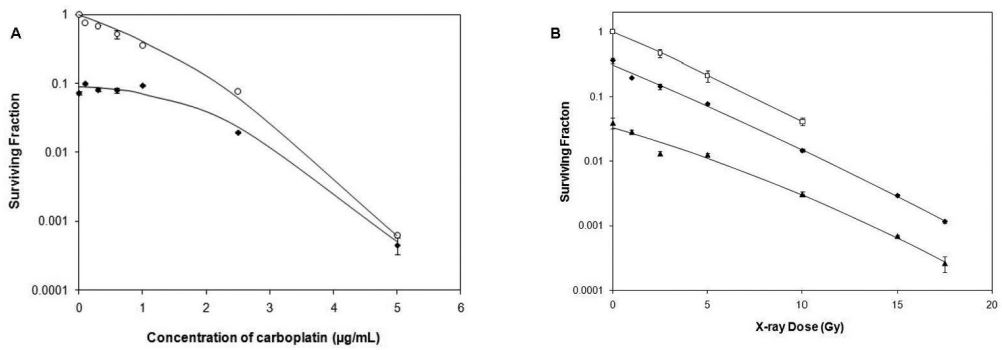

Fig. 1.

A. Clonogenic survival of F98 glioma cells following treatment with carboplatin alone or in combination with X-irradiation. A. S.Fs were determined for the F98 glioma cells either treated with carboplatin alone $(\bigcirc)$ or followed by X-irradiation (7 Gy) $(\diamond)$. The $\mathrm{D}_{10}$ value for cells treated with carboplatin alone was $2.5 \mathrm{ug} / \mathrm{mL}$. The combination of carboplatin pretreatment followed by X-irradiation reduced the S.F. to 0.0194. The S.F. after treatment with $5 \mu \mathrm{g} / \mathrm{mL}$ of carboplatin either alone or in combination with $\mathrm{X}$-irradiation was $<0.0006$. B. S.Fs of F98 cells either untreated $(O)$ or pretreated with carboplatin at concentrations of 1 $\mu \mathrm{g} / \mathrm{mL}(\bullet)$ or $2.5 \mu \mathrm{g} / \mathrm{mL}(\boldsymbol{\Delta})$, followed by varying doses of X-rays (1 to $17.5 \mathrm{~Gy}$ ). Data points are expressed as mean \pm S.D. $(n=3-5)$. 

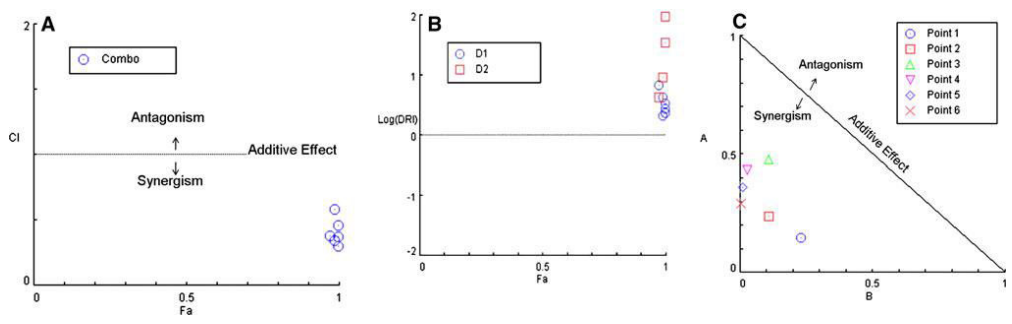

Fig. 2.

Analysis of clonogenic survival data shown in Fig. 1. A. Combination index (CI) plot based on the Chou-Talalay equation (29-31) and the computerized quantitation (32). The CI was plotted as a function of fractional effect levels $\left(f_{a}\right)$ (e.g., for $50 \%$ inhibition, $f_{a}=0.5$ ) where $\mathrm{CI}<1,=1$, and $>1$ indicate synergism, additive effect and antagonism, respectively. $\mathrm{B}$. Normalized isobologram for the non-constant ratio combinations. The normalized doses are given on the $\mathrm{y}$ - and $\mathrm{x}$-axis for $\mathrm{X}$-irradiation $\left(\mathrm{D}_{1} / \mathrm{Dx}_{1}\right)$ and carboplatin $\left(\mathrm{D}_{2} / \mathrm{Dx}_{2}\right)$, respectively. When a combination data point falls on the diagonal, it indicates additive effect, and when it falls in the lower left or upper right quadrants of the diagonal, it indicates synergism or antagonism, respectively (31). C. $\mathrm{F}_{\mathrm{a}}$-DRI plot where the dose-reduction index (DRI) was plotted as a function of the fractional effect levels $\left(f_{a}\right)$. DRI indicates how many folds dose-reduction would be allowed at a given effect for the synergistic combination. Therefore, DRI $>1$ or $\log (\mathrm{DRI})>0$ indicates favorable dose-reduction, and $\mathrm{DRI}<1$ or a negative log (DRI) value indicates an unfavorable dose reduction (31). The log (DRI) used here was selected to avoid high DRI values from falling out of scale. All plots were generated automatically by computer software (32) after entering dose-effect data into the computer for the drug alone or $\mathrm{X}$-irradiation, and their combinations. 

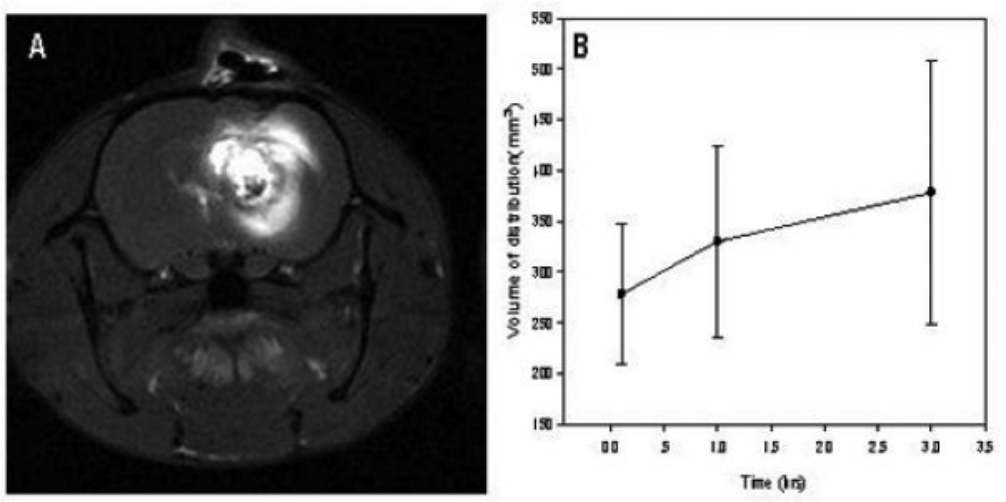

Fig. 3.

A. Volume of distribution of carboplatin determined by MRI. The volumes of distribution $\left(\mathrm{V}_{\mathrm{d}}\right)$, as calculated from T1-weight images following CED of $20 \mu \mathrm{g}$ carboplatin mixed with Gd-DTP. The $\mathrm{V}_{\mathrm{d}}$ was $278-377 \mathrm{~mm}^{3}$ between $0.5-3$ hours following CED of $20 \mu \mathrm{L}$ of the infusates. B. T1-weighted axial image of an F98 glioma bearing rat. A mixture of carboplatin $(20 \mu \mathrm{g}$ in $10 \mu \mathrm{L})$ and a 1:70 dilution of Gd-DTPA were administered by means of CED over $30 \mathrm{~min}$. Magnetic resonance imaging was carried out $1 \mathrm{hr}$ later. Intense uptake of Gd can be seen in the tumor and in peritumoral white matter indicating efficient dispersion of the mixture by means of CED. Data points are expressed as mean \pm S.D. $(n=3-4)$. 


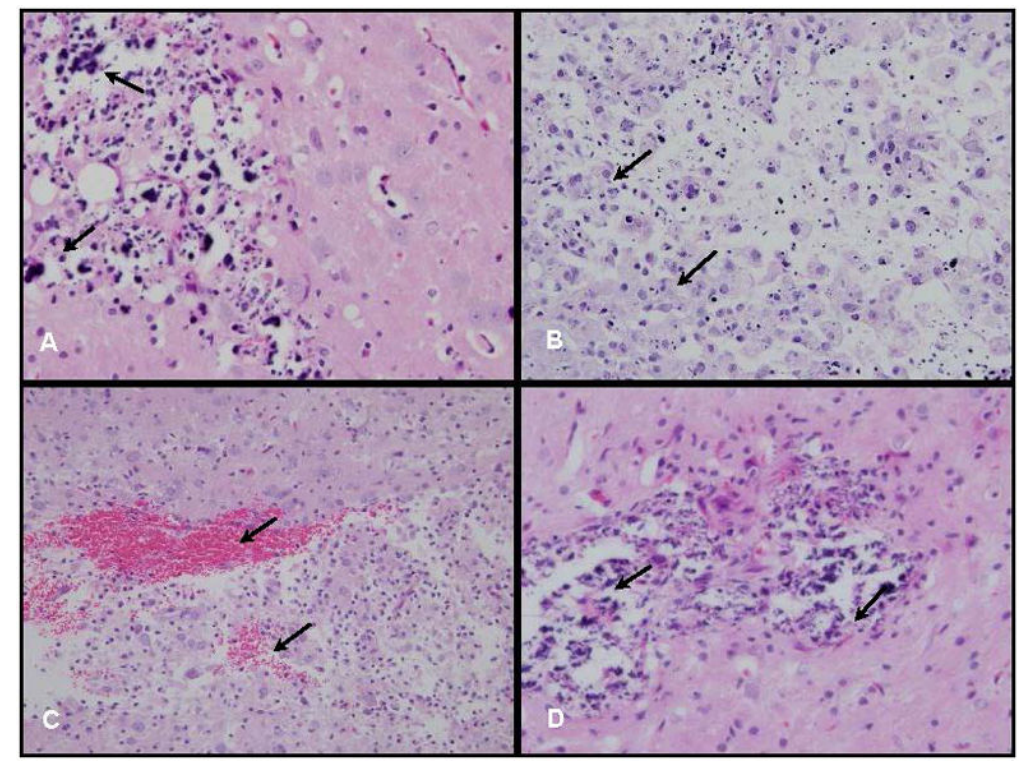

Fig. 4.

Neuropathologic changes. A. Brain of long term surviving F98 glioma bearing rat that had received $20 \mu \mathrm{g}$ of carboplatin by $\mathrm{CED}$, followed by three $5 \mathrm{~Gy}$ fractions of X-rays, and was euthanized at $180 \mathrm{~d}$. No residual tumor cells were identified. There was a light infiltrate of lymphocytes with scattered clumps of dystrophic calcific debris $(400 \times)$. B. Brain of a nontumor bearing rat that had received $40 \mu \mathrm{g}$ of carboplatin $(10 \mu \mathrm{L})$ by CED and was euthanized 3 weeks later. There was focal necrosis of white matter at the site of administration, an infiltrate of foamy macrophages and scattered lymphocytes $(200 \times)$. C. Same animal as (B) but another area within the white matter that showed microscopic foci of hemorrhage and an infiltrate of foamy macrophages $(200 \times)$. D. Brain of a non-tumor bearing rat that received $40 \mu \mathrm{g}$ of carboplatin by CED followed by three $5 \mathrm{~Gy}$ fractions of X-rays and was euthanized 3 weeks later. There was white matter necrosis, scattered lymphocytes and macrophages, and calcified cellular debris $(400 \times)$. Based on these observations a dose of $20 \mu \mathrm{g}$ of carboplatin alone or in combination with X-irradiation was selected for therapy studies. 

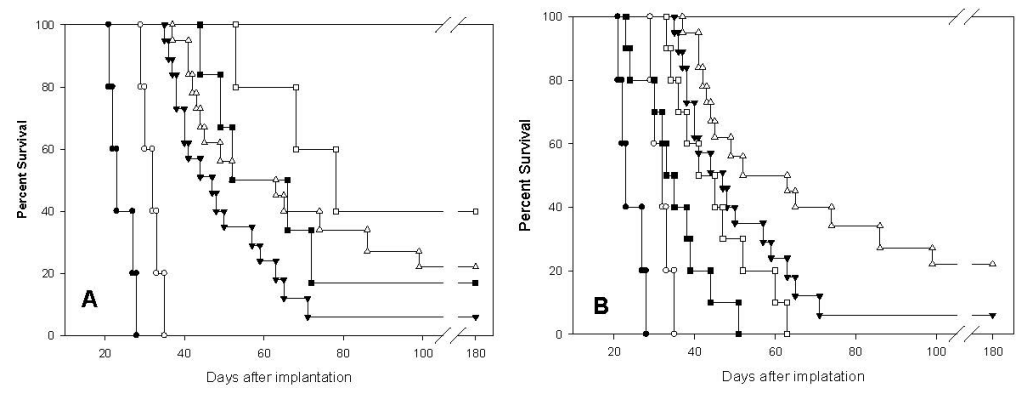

Fig. 5.

A. Kaplan-Meier survival plots of F98 glioma bearing rats following administration of carboplatin or by Alzet pumps alone or in combination with X-irradiation. Survival time in days after implantation have been plotted for untreated animals (O), X-irradiation only (15 Gy) (O), CED of carboplatin ( $\mathbf{\nabla})$, CED of carboplatin $(20 \mu \mathrm{g}$ over $30 \mathrm{~min})+\mathrm{X}$-irradiation $(\triangle)$, carboplatin, administered by Alzet pumps (84 $\mu \mathrm{g}$ g over $7 \mathrm{~d})(\boldsymbol{\square})$, carboplatin, administered by Alzet pumps $+\mathrm{X}$-irradiation $(\square)$. B. Kaplan-Meier survival plots of rats F98 glioma bearing either small $\left(\sim 20-25 \mathrm{~mm}^{3}\right)$ or large $\left(\sim 60-80 \mathrm{~mm}^{3}\right)$ tumors. Survival times in days after implantation have been plotted for untreated controls $(\mathbf{O})$, irradiated rats $(\mathrm{O})$, CED of carboplatin in rats with small tumors $(\boldsymbol{\nabla})$, CED of carboplatin $+\mathrm{X}$-irradiation in rats with small tumors $(\triangle)$, CED of carboplatin in rats with large tumors $(\square)$, CED of carboplatin $+\mathrm{X}$-irradiation in rats with large tumors $(\square)$. 


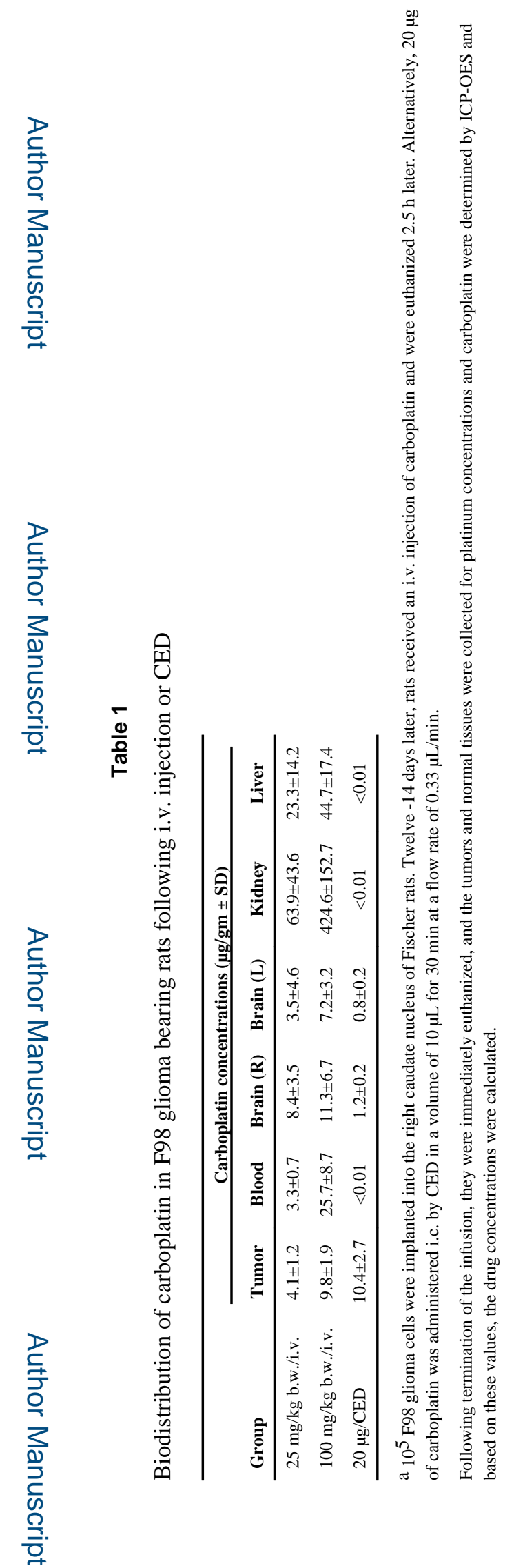

J Neurooncol. Author manuscript; available in PMC 2015 July 06. 


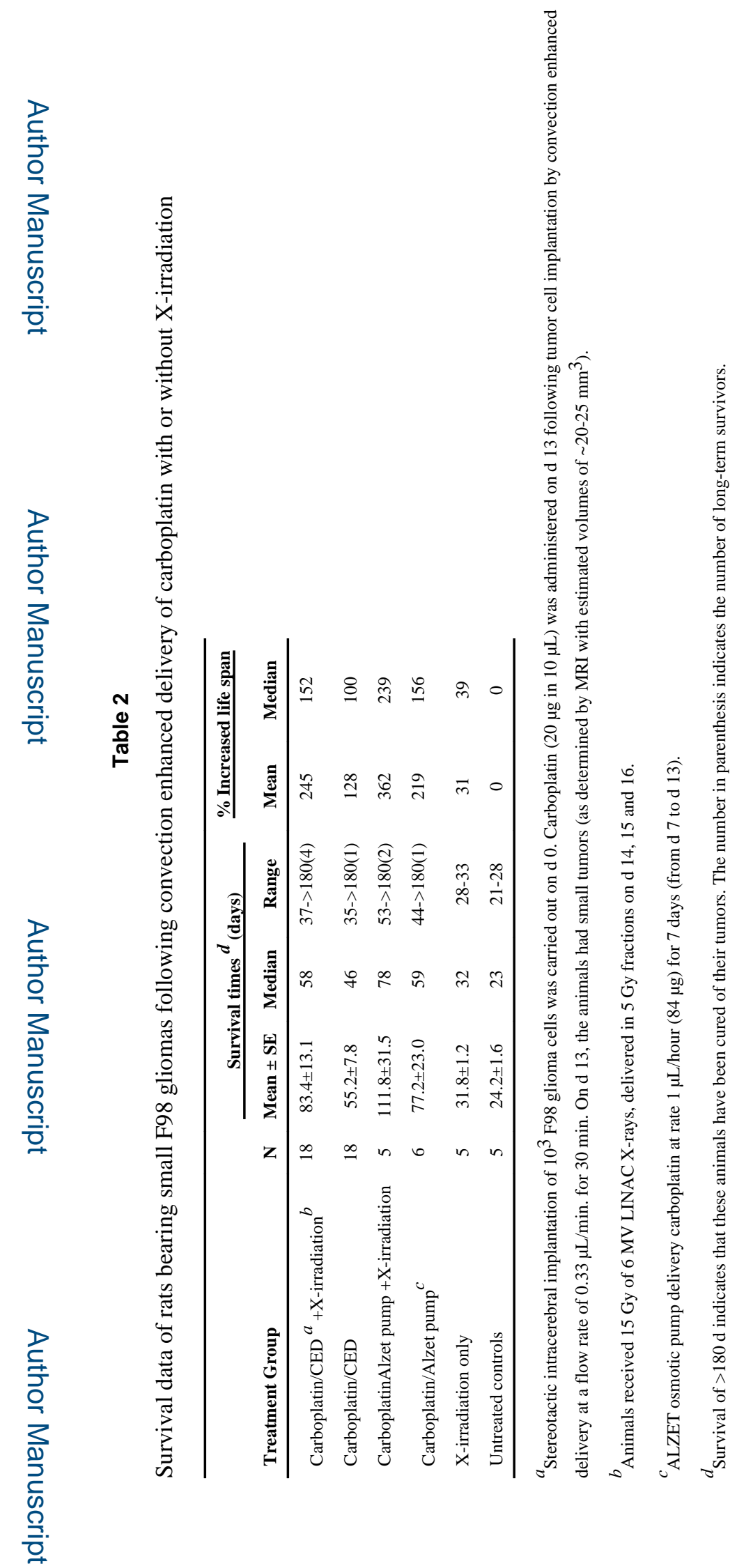

J Neurooncol. Author manuscript; available in PMC 2015 July 06. 


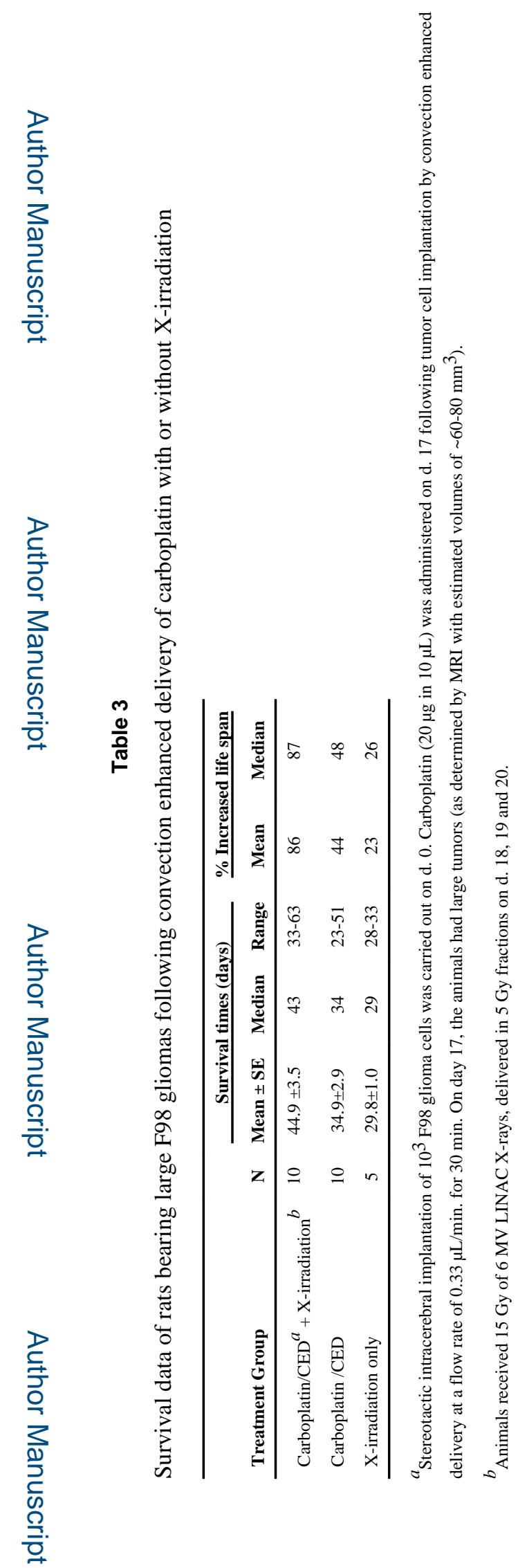

J Neurooncol. Author manuscript; available in PMC 2015 July 06. 


\section{로을}

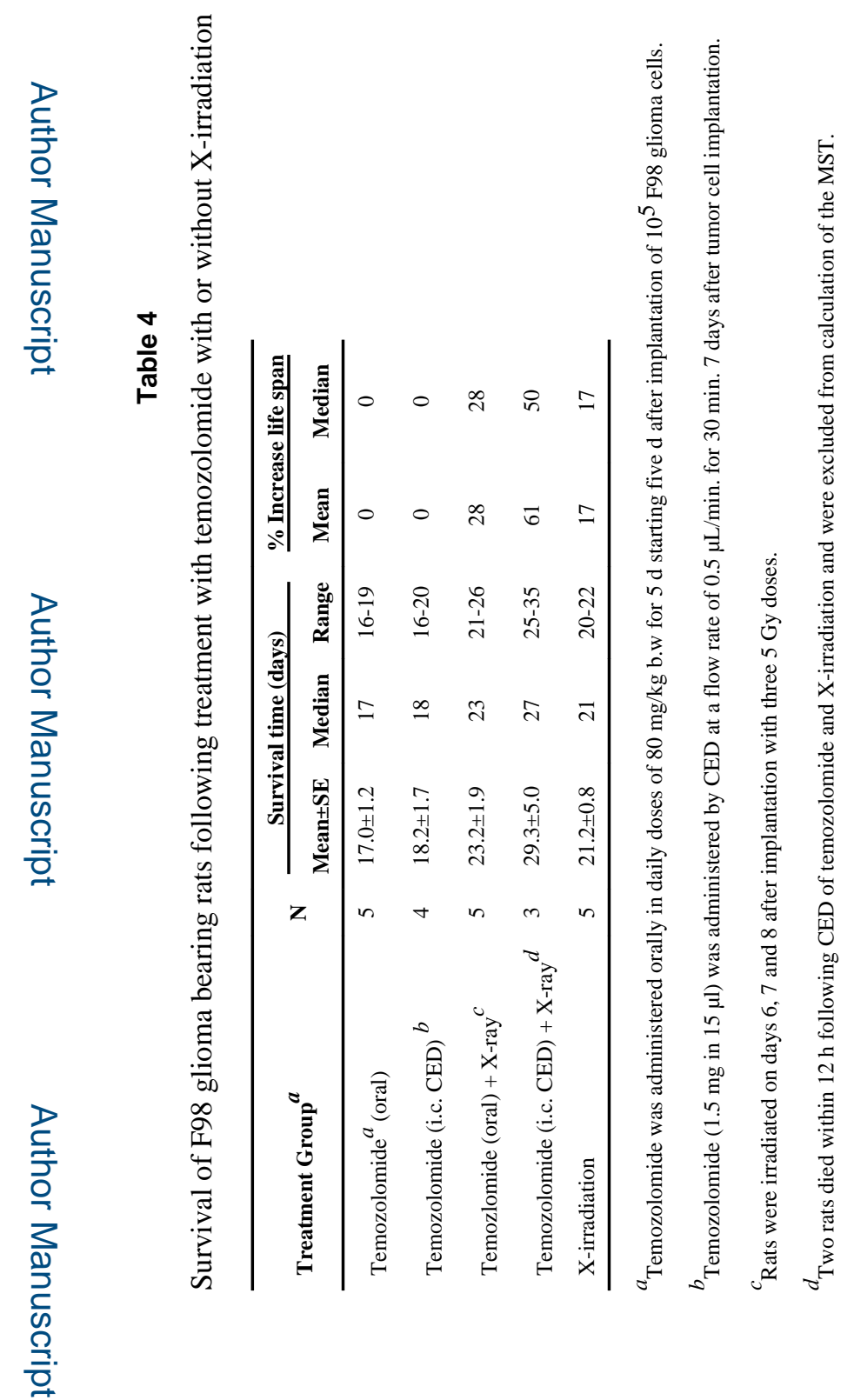

J Neurooncol. Author manuscript; available in PMC 2015 July 06. 